\title{
PUBLICACIONES CIENTÍFICAS Y SU APOYO POR REDES ACADÉMICAS EN TIEMPOS DE PANDEMIA
}

\author{
Lisandro Jose Alvarado-Peña* \\ https://orcid.org/0000-0001-5097-811X
}

\begin{abstract}
Como citar: Alvarado-Peña, Lisandro José. (2021). Publicaciones científicas y su apoyo por redes académicas en tiempos de pandemia. Telos: revista de Estudios Interdisciplinarios en Ciencias Sociales, 23 (2), Venezuela. (Pp. 201-205).

DOI: www.doi.org/10.36390/telos232.01
\end{abstract}

Este número es el esfuerzo de trabajo de más de 8 meses, por parte de los articulistas, editor en jefe, comité científico, evaluadores y editor invitado, en el cual se presentan una variedad de temas que ha sido impactados por la pandemia y siguen siendo afectados por la evolución del virus, situación que ha venido afectando paulatinamente a otros países de la región y el mundo. Esto sin dudas, ha marcado lo que se pensaba que era la nueva normalidad para el año 2021 y la situación de casos es cada vez más alarmante; por las nuevas medidas de confinamiento que para el primer semestre de este año se están tomando en cada país, incluso para el resto del año. Se pensaba una nueva normalidad con las escuelas y las universidades abiertas, el proceso de enseñanza aprendizaje en modalidad mixta y hoy día, es una realidad que la virtualidad es la reina de todo ese proceso.

Sin bien, es cierto, un pilar sustantivo, como es la investigación en nuestras instituciones de educación superior y/o organismos de investigación, sin embargo, sus presupuestos se han visto afectado o disminuido por la redistribución de recursos por parte de los Estados, para atender asuntos prioritarios producto de la pandemia. Ante esto, el apoyo para investigación y publicaciones científicas ha sido afectado y, por lo tanto, los indicadores de calidad de estas IES. El apoyo se ha centrado en investigaciones del COVID-19 y publicaciones en revistas de factor de impacto.

En ese sentido, este número 23-2 (Mayo-Agosto de 2021), en conjunto entre la red REOALCEI y la revista científica arbitrada de Estudios Interdisciplinarios en Ciencias Sociales (TELOS), revista registrada en ESCI que es parte de la mejores bases de datos a nivel mundial WEB of SCIENCES (WOS) por su alta calidad en los procesos

\footnotetext{
* Doctor en Ciencias Sociales, mención: Gerencia. Diploma de Estudios Avanzados (DEA) dentro del Doctorado en Administración de Empresas en la Universidad Politécnica de Madrid (UPM)- España. Posdoctorado en Metodología de la Investigación, Socioformación y Desarrollo Humano en el Centro Universitario CIFE, México (en curso). Profesor e investigador de la Universidad del Zulia. Director ejecutivo de la Red Académica Internacional "Estudios Organizacionales en América Latina, el Caribe e lberoamérica" (REOALCEI). Correo electrónico lisandroinvestigacion@gmail.com
} 
editoriales que realizan, presentan artículos que se han venido evaluando por pares ciegos y por el comité editorial de la revista, que se señalan a continuación:

La gestión del conocimiento en la carrera de educación primaria en la universidad nacional del santa, Perú, donde se analizan tres dimensiones, creación; transferencia - almacenamiento; aplicación y uso del conocimiento; en el cual se propuso una herramienta para mejorar la gestión del conocimiento en la carrera de educación primaria, porque la percepción de los estudiantes es mala, debito a esto, amerita un proceso de mejora continua.

El siguiente artículo, lectura en derecho: sugerencias para guiar al estudiante en su proceso formativo y en la apropiación del conocimiento, se describen estrategias de lectura que caracterizan a los expertos en este campo y herramientas más eficaces de enseñanza, que permiten a los alumnos leer las sentencias con un propósito definido, conozcan las características estructurales de los textos y les permita abordar de manera flexible y crítica los fallos.

Asimismo, y en el orden que corresponde de esta edición, el nivel de satisfacción en la formación de calidad a nivel universitario, destaca la superación personal de cada estudiante en lograr los conocimientos y habilidades que permitan un desarrollo de calidad en el área profesional en la cual van a desempeñarse a futuro y demostrar las capacidades aprendidas, que se corresponde con su objetivo formulado y con un alto resultado de satisfacción por la calidad de formación recibida de la institución.

Hasta aquí los artículos presentados resaltan la importancia del apoyo y servicios académicos y de investigación por parte de las IES, buscando que sean de calidad y donde la atención debe estar centrada en los estudiantes.

En el siguiente artículo,da prioridad al área ambiental, con el artículo percepción de los servicios ambientales de provisión en la reserva natural Pacoche, resaltando que los servicios ambientales de provisión, son los bienes o recursos proporcionados por los ecosistemas (terrestres o marino), dichos servicios ambientales han sido aprovechados desde siempre por los seres humanos; es determinante esta investigación al concluir, que el flujo de estos servicios y principalmente el recurso hídrico se ha visto impactado en su disminución, a causa del aumento demográfico, la explotación de recursos naturales y el efecto del cambio climático.

El quinto artículo de esta edición, con énfasis en el proceso de enseñanza-aprendizaje en educación, relativo a, prácticas pedagógicas en la formación docente: desde el eje didáctico, trata sobre la formación inicial del docente, proceso que tiene como propósito el desarrollo de competencias relacionadas con el saber didáctico para ejercer el ejercicio profesional, los sujetos en formación deben desarrollar una serie habilidades concretadas en propuestas didácticas, por lo tanto, este artículo formula lineamientos que fomenten la práctica pedagógica profesional en la formación docente para el ejercicio didáctico en el programa de Licenciatura en Pedagogía Infantil; resultando la comprensión y aplicación de conocimientos prácticos y metodológicos. 
El artículo sexto, referido a la aproximación teórica para entender la violencia desde un enfoque crítico, presenta como objetivo un acercamiento teórico a la violencia, a partir de la exploración de las aportaciones teóricas de algunos autores que analizan o retoman este concepto desde una perspectiva crítica. Resaltando que, sin subestimar la perspectiva teórica con que se examine la violencia, para tener los elementos necesarios y lograr un mejor conocimiento del fenómeno de la violencia, es necesario ligarla a otros conceptos como: poder, conflicto, dominación, explotación y discurso hegemónico.

Se presenta el artículo: La sostenibilidad como estrategia competitiva en empresas del sector construcción del departamento de Antioquia - Colombia, cuyo objetivo fue analizar la sostenibilidad como estrategia competitiva en las empresas del sector construcción en el departamento de Antioquia, Colombia. Se determinó que las empresas del sector tienen una tendencia favorable en la implementación de la sostenibilidad en sus tres dimensiones en la gestión de sus proyectos y en las diferentes áreas, sin embargo, hoy se encuentra deficiencia en la implementación de éstas, como ventaja competitiva ya sea por costos 0 diferenciación.

El modelo de gestión del conocimiento para centros de productividad e innovación analiza una organización creada en el año 2000 y cuyos trabajos en pro de la competitividad regional son reconocidos en el ámbito nacional. Esta organización -CREPIC- se destaca por su creación a partir de la política pública en materia de ciencia y tecnología en Colombia; como resultante, un modelo de gestión de conocimiento alineado con la naturaleza de la organización, las particularidades del territorio y los aportes bibliográficos en la materia. En este artículo y el anterior, se analizan aspectos como la competitividad, productividad e innovación en empresas e instituciones, que generan un valor distintivo a esta fórmula para la gestión del conocimiento.

El noveno artículo, competencias de liderazgo en el proceso de enseñanza aprendizaje de los administradores de empresas de la Universidad de Manizales, hace referencia a las competencias de la práctica empresarial, las básicas del liderazgo gerencial y las específicas de liderazgo; esenciales en el proceso formativo de los administradores de empresas de la Universidad de Manizales, teniendo en cuenta tanto las reflexiones y perspectivas del Proyecto Tuning América Latina periodo 2011-2013; como el perfil profesional y ocupacional propuesto por el programa y demás competencias que se requieren para dar solución a temas empresariales. Asimismo, el décimo artículo, pensamiento estratégico de Whittington. Una mirada epistemológica a su concepción, donde se analiza la concepción de Whittington (2003) sobre las estrategias gerenciales, en lo que se demarca la frontera científica entre el enfoque moderno y postmoderno, 
encontrándose en la vanguardia científica y dando apertura a investigadores y empresarios a profundizar el estudio de las estrategias gerenciales.

Se destaca en los últimos dos artículos la relevancia de temas empresariales, como las competencias de liderazgo y sus impacto en el sector empresarial; al igual el tema del pensamiento según teorías, para el estudio de generación de estrategias gerenciales y que benefician a diferentes actores en sus organizaciones.

Los artículos que se destacan a continuación en el área de economía y con visiones de varios países: Empleo en la economía informal: mayor amenaza que la pandemia del covid-19; en donde se realizó un análisis reflexivo sobre el empleo en la economía informal en tiempos de pandemia provocada por el COVID 19. Los resultados indican que los gobiernos deben dar el apoyo a quienes tienen empleos informales, creando estructuras justas, resilientes y éticas para los trabajadores, las industrias, las economías y sociedad en general. El articulo doce, rezagos de la inflación en la economía venezolana respecto a la oferta monetaria, que tuvo como objetivo determinar los rezagos de la inflación en la economía venezolana respecto a la oferta monetaria; demostrándose que la adopción de una política monetaria en Venezuela de carácter expansivo o restrictivo, de forma inmediata se trasmite al sistema de precios y de créditos de la banca.

En el siguiente artículo los investigadores, presentan una investigación de carácter internacional y que es producto de una investigación más amplia, adscrita al Instituto de Investigaciones de la RED REOALCEI, se titula: Realidad y perspectivas de los Centros de Investigación Universitarios en América Latina ante el Covid-19, donde se describió la realidad y perspectivas de los Centros de Investigación Universitarios en América Latina ante el Covid-19, a través de una revisión sobre la bibliografía existente. Los hallazgos más relevantes, es la poca importancia y baja asignación presupuestaria que a nivel gubernamental se le otorga a la investigación dentro del sector universitario, destacando que estas han sabido salir adelante, incorporando los medios digitales a sus actividades en tiempos de pandemia y otras fórmulas para continuar con el proceso investigativo, como misión sustantiva de estos organismos.

El siguiente artículo: Cansancio emocional en médicos anestesiólogos, como factor asociado al síndrome de Burnout por el Covid-19, es producto de una investigación doctoral, y describe el cansancio emocional en médicos anestesiólogos como factor asociado al estrés laboral crónico o síndrome de Burnout por el Covid-19, en base a los fundamentos del origen del término Burnout introducido por Freudenberger en 1974 y las investigaciones de Maslach y Jackson desde el año 1982 hasta resultados de actuales investigaciones publicadas en revistas arbitradas de alto impacto sobre el tema estudiado.

El último artículo de la sección se titula: Calidad editorial, versus editoriales depredadoras, en donde se analizaron las actuaciones de las editoriales 
depredadoras, debido al crecimiento de las mismas y sus malas prácticas en la gestión editorial, identificándolas como una problemática actual, por no garantizar las revisiones de pares evaluadores y buenas prácticas editoriales.

Estos tres últimos artículos, reflejan claramente, la realidad del proceso de gestión en centros de investigación, investigación en el área de medicina y la realidad hoy día, en los procesos editoriales, sus aspectos implícitos y explícitos referente a la calidad.

Luego, se presenta un documento en esta edición: Procesos de construcción, emisión de dióxido de carbono y resultados socio-económicos durante la pandemia del covid-19 en México.

El mismo, describe cómo son llevados a cabo los procesos de construcción y las emisiones de Dióxido de Carbono que influyen en los resultados socio-económicos de México, en tiempos de pandemia del Covid, resulta importante crear indicadores que proporcionen información sobre la cantidad de $\mathrm{Ton}^{-\mathrm{CO}_{2}}$ generada en los procesos constructivos en general y especialmente, ahora que muchos de estos procesos se han detenido a raíz de la emergencia sanitaria del Covid-19.

Por último y para cerrar esta edición, se presenta una reseña del libro: Gestión organizacional, sustentabilidad, innovación y emprendimiento en América Latina, de los editores académicos Oswaldo Ospina Mejía y Lisandro José, AlvaradoPeña, presentada por el destacado académico e investigador Gumaro Alvarez Vizcarra, del Tecnológico de Monterrey, México.

Desde la red REOALCEI, estamos muy complacidos como siempre de hacer estas alianzas estratégicas para la difusión y divulgación de las investigaciones de nuestros miembros activos. Casi una década nos ha permitido estar unidos con la revista Telos, ha sido una alianza de muchos frutos, regocijos, buenas noticias y lo más importante es que cada investigador, con sus publicaciones pueda ir creciendo en el sistema nacional de investigadores de sus países, es un gran aporte de estas alianzas.

Nuestra gratitud a las autoridades de la revista Telos y a su equipo editorial. Con aprecio a todos. 